\title{
One step is not enough: Making better use of association norms to predict cued recall
}

\author{
DOUGLAS L. NELSON, DAVID J. BENNETT, and TODD W. LEIBERT \\ University of South Florida, Tampa, Florida
}

\begin{abstract}
Cued recall is strongly affected by the strength of the preexisting connection between the test cue and the information to be recalled, the target. In all past work, preexisting cue-to-target strength has been measured by the probability that the cue produced the target in free association. This paper presents four experiments showing that this use of such norms underestimates the strength of the connection and that a more accurate estimate can be obtained by incorporating indirect as well as direct connections in the estimate. Experiments 1 and 2 showed that in extralist cued recall both the strength and number of two-step indirect connections facilitate recall. Experiment 3 showed that three-step connections have negligible effects. Experiment 4 used an intralist task in which cue and target are first studied together, and the results showed once again that indirect connections can affect recall. In all of these experiments, indirect connections had an effect on recall that was larger when direct cue-to-target strength was weak than when it was strong. Implications for using association norms in research are described, and an algorithm for using association norms to measure cueto-target strength is proposed.
\end{abstract}

The present article is concerned with using wordassociation norms as an index of preexisting connection strength among related words in order to predict performance in various tasks, such as cued recall (e.g., Bahrick, 1970; Nelson \& McEvoy, 1979), free recall (Deese, 1965), lexical decision (Canas, 1990; deGroot, Thomassen, \& Hudson, 1982; McNamara, 1992), and picture naming (e.g., McEvoy, 1988). Such norms are often collected by providing people with a word and asking them to produce the first related word to come to mind. Following a long tradition in memory research (cf. Cramer, 1968 ), the probability with which any particular word is produced in a large sample of people is used as an index of the strength of a connection between the given word and the produced word. Using the word "strength" only in a descriptive sense, words produced by many people are said to be more strongly connected to the given word than are those that are produced by fewer people. As with other types of normative data, association norms codify consensual knowledge and allow researchers to make predictions about the consequences of deviating from modal values (Kahneman \& Miller, 1986). For example, given that two words each produce " $X$ " as an associate, the word that produces " $X$ " with a higher probability in the norms should also be more effective as a retrieval prompt in cued recall.

This research was supported by Grant MH 16360 to D. L. Nelson from the National Institute of Mental Health. The authors are indebted to Cathy McEvoy, Tom Nelson, and two anonymous reviewers for their comments on an earlier draft of the paper. Requests for reprints should be sent to D. Nelson, Department of Psychology, University of South Florida. Tampa, FL 33620 (e-mail: nelson@luna.cas.usf.edu).
The present experiments were designed to determine whether normatively determined measures of indirect connections have any effect on cued recall above and beyond effects related to direct connections. Direct connections refer to immediate, uninterrupted connections between two words as traditionally measured by free association norms. Indirect connections consist of mediated connections (e.g., Jenkins, 1963; McNamara, 1992) and converging connections (e.g., Cofer, 1968) which also can be measured through the use of association norms. For example, according to such norms, POET is directly connected to AUTHOR because it produces this word directly in free association. These two words also share indirect mediated connections (e.g., POET produces writer which produces AUTHOR) as well as converging connections (e.g., both POET and AUTHOR produce book as an associate).

Theoretical interest in the effects of both direct and indirect connections has had a long and venerable history that began philosophically with Aristotle and the British associationists (e.g., Deese, 1965), that extended through the verbal learning period (e.g., Cofer, 1968; Jenkins, 1963), and that continues to the present day (McKoon \& Ratcliff, 1992; McNamara, 1992; Nelson, Schreiber, \& McEvoy, 1992). Our interest in these connections was motivated by our attempt to develop a model of cued recall, called PIER, ${ }^{1}$ which was specifically designed to explain how cue-to-target strength and other variables related to preexisting memories affected the recall of recently studied words (Nelson et al., 1992). Knowing how preexisting memories affect cued recall is critical, because memory retrieval in everyday life situations is often driven by cues that differ from but are related to the targeted information as a result of previous experience in 
other contexts. Decades of research have shown that words can be effective recall prompts because of direct connections to the targeted information established before an experimental session (e.g., Bahrick, 1970; Nelson \& McEvoy, 1979; Nelson et al., 1992). The question motivating the present experiments was whether indirect connections would contribute to cued recall performance above and beyond the contribution produced by direct connections.

If indirect connections have little or no effect on recall under a wide variety of learning and testing conditions, then we can reasonably assume that traditional methods for indexing preexisting strength between two related words are satisfactory. Alternatively, if indirect connections facilitate recall, then we can assume that such connections play some role in the retrieval process. Such a result would complicate the use of normative data in measuring preexisting cue-to-target strength and would suggest that both direct and indirect connections need to be assessed and perhaps incorporated into an index of preexisting strength that captures both sources of information. Although the present experiments were not designed to provide crucial tests of specific controversies in the literature (e.g., McKoon \& Ratcliff, 1992; McNamara, 1992), such a result could have important implications for research that relies (or should rely) on indices of preexisting strength. Knowing that indirect connections can affect cued recall and knowing how they can be combined with direct connections may be useful in selecting materials for research in a variety of domains.

In Experiment 1, subjects studied words in the absence of contextually related words that might have biased their encoding, for example, AUTHOR was presented alone in a list of other unrelated words. At the end of the study period, retrieval cues were presented one at a time to prompt the recall of each studied word (e.g., POET was presented as a retrieval cue for AUTHOR). This procedure conforms to an extralist cuing task. Retrieval in this task must be based on preexisting connections between the cue and target, because the words used as retrieval cues are not studied with their targets. A single-response norming task was used to index both direct cue-to-target strength and indirect cue-to-target strength at both high and low levels by selecting word pairs with the desired characteristics from a normative database that comprised thousands of words. A single- as opposed to a multipleresponse task was used to avoid problems with response chaining and retrieval inhibition (McEvoy \& Nelson, 1982). Moreover, the single-response procedure is presumably more conservative in establishing direct connections, because it avoids the production of responses in the context of other related words.

Experiment 1 also varied the number of associates linked to the studied target words. In the extralist cuing task, targets with smaller associative sets have a substantial advantage in cued recall over those with larger sets, and this advantage is attributed to the greater probability of sampling the target when set size is small than when it is large (e.g., Nelson et al., 1992). Our original intent was to determine whether the magnitude of obtained set-size effects would vary with direct and indirect cue-to-target strength, but this intent became overshadowed by our growing interest in the relationship between the two strength manipulations. Set-size findings will be reported, but they will be treated as secondary findings to maintain the emphasis on the relationship between direct and indirect strength.

Experiment 2 replicated and extended the results of Experiment 1 by separating the relative effects of the number of indirect connections from their strength, and Experiment 3 investigated the potential effects of threestep mediated connections between the test cue and target in the extralist cuing task. Experiment 4 focused on the role of indirect connections in the intralist cuing task. This task differs from extralist cuing in that the words used as test cues are paired with the target words during the study trial. The intralist task is interesting, because manipulations of preexisting strength can be varied over a very wide range and yet reasonable levels of recall can be attained because of episodically established connections. These experiments focused on determining whether preexisting indirect connections would have any effect in this task, particularly at the very weakest levels of direct strength.

\section{EXPERIMENT 1}

\section{Method}

Design and Subjects. The design formed a $2 \times 2 \times 2$ mixedmodel factorial, with direct cue-to-target strength varied between subjects (strong, weak) and indirect strength (high, low) and target set size (small, large) varied within subjects. Forty-eight university students from courses in introductory psychology participated in the experiment and received course credit for their efforts. Twenty-four were randomly assigned in order of appearance to the strong-cue condition, and the remaining 24 were similarly assigned to the weak-cue condition. Within each of these conditions, half of the subjects were assigned to one list and the remaining half were assigned to another list.

Materials. Normative estimates of direct and indirect strength, target set size, and other word characteristics were available for $4,000+$ words, and these estimates were used in constructing two lists that are presented in Appendix A. In the normative task, an average of 152 students each responded by writing the first word that came to mind for each word listed in a booklet containing approximately 120 words (Nelson, McEvoy, \& Schreiber, 1994). Set size for each normed word was estimated by counting the number of different words provided by 2 or more subjects (e.g., see Nelson \& Schreiber, 1992, for more details). As shown in the appendix, 24 words served as targets in each list, with half defining small and half defining large sets of associates (e.g., RAZOR had a small set of 5 associates, and CAR had a large set of 25 associates). Targets with small sets averaged 6.88 associates $(S D=1.42)$, and those with large sets averaged 19.71 associates $(S D=2.35)$. Because recall in the extralist cuing task also varies as a function of other target characteristics, such as concreteness (Nelson \& Schreiber, 1992), printed frequency (Nelson \& Xu, 1995), and the connectivity of their associates (Nelson, Bennett, Gee, Schreiber, \& McKinney, 1993), these variables were controlled across differences in set size. Mean concreteness, frequency, and connectivity values were, respectively, $5.08(S D=1.40)$. $86(110)$, and 1.81 (.69). Hence, at each level of set size, the targets were relatively concrete and moderately frequent (Kučera \& Francis, 1967), and their associates were moderately interconnected. 
The test cues used to prompt the recall of these targets were also taken from the association norms. The number of associates linked to each cue was held constant across all conditions and averaged 13.48 associates $(S D=3.67)$. Direct cue-to-target strength was indexed, according to tradition, by calculating the proportion of times that a particular target was produced as a response to a cue word. Strong direct-strength cues produced targets with a relatively high probability in the norms of $.27(S D=.04)$, and weak direct-strength cues produced them with a relatively low probability of $.06(S D=.02)$. As shown in Appendix A, the same targets were used in both conditions of cue-to-target strength whenever possible.

Indirect cue-to-target strength was varied by selecting cue-target pairs that differed in number of shared associates and mediated connections. The mean number of shared associates and mediated connections for high levels of indirect strength were, respectively, $4.69(S D=1.48)$ and $3.85(S D=2.25)$; for low levels, these values were $1.12(S D=.87)$ and $1.30(S D=1.40)$. Target set size, direct strength, and indirect strength were carefully equated at each level of the other two variables.

In addition to counting the numbers of indirect connections, the strength of such connections was determined by using the normative probabilities for each link in the chain to compute the transition probabilities (Ratcliff \& McKoon, 1988). For example, the normative probability that BLADE produces sharp is .10 , and the probability that sharp produces RAZOR is .03 . Similarly, the probability of BLADE producing shave is .02 , and the probability of shave producing RAZOR is .15. The strength of the mediated connections $\left(I_{\mathrm{m}}\right)$ between these two words was indexed by calculating the multiplied and summed strengths of the individual mediated connections [i.e., $(.10 \times .03)+(.02 \times .15)=.006]$. More generally, indirect mediation strength between any two words can be indexed by:

$$
I_{m}(i, j)=\sum_{m} S_{i m} S_{m j},
$$

where $i$ is the test cue, $j$ is the target item, and $m$ are all the mediating links connecting the two words. Using this algorithm, the indices for indirect mediated connections in the present experiment were $.04(S D=.05)$ for high mediated st rength and $.01(S D=.03)$ for low mediated strength. Using a similar algorithm, we calculated the strength of the indirect converging mediators $\left(I_{c}\right)$; that is,

$$
I_{c}(i, j)=\sum_{c} S_{i c} S_{j c} .
$$

With this measure, the estimates for high and low converging strengths were $.06(S D=.07)$ and $.01(S D=.02)$. With these algorithms, the range of indirect strength was relatively modest but in the same direction as the measures that were based on the number of indirect connections, a point that will be reconsidered in Experiment 2.

Procedure. Subjects participated in individual sessions and received a single study-test trial. During study, the target words were presented in uppercase letters by a Kodak slide projector at a 6-sec rate, and all words were read aloud by the subject when presented. The subjects were asked to remember as many targets as possible without being told how they would be tested. Particular learning strategies were not suggested. Just before being shown the study list, all subjects were shown a short list of people's names to familiarize them with the presentation rate.

The test instructions were read to the subjects immediately following the last study presentation. These instructions indicated that a meaningfully related test cue would be shown to help them recall each word in the list, that the cue should first be read aloud, and that then an attempt should be made to recall the list word. Clarifying examples were included. This test trial was self-paced, and guessing was encouraged but not required. Finally, the order of the test cues and the study words was unsystematically randomized for each subject.

\section{Results}

The results of Experiment 1 are presented in Table 1, and, as can be seen, probability of correct recall was greater for strongly related cues $(.77)$ than for weakly related cues (.47) and for cues with high (.68) as opposed to low (.56) levels of indirect strength. Recall probability was also greater for targets with small (.69) than for targets with large sets $(.55)$. The results of a mixedmodel analysis of variance showed that direct cue-totarget strength $\left[F(1,46)=60.93, M S_{\mathrm{e}}=.067\right]$, indirect strength $\left[F(1,46)=22.09, M S_{\mathrm{e}}=.036\right]$, and target set size $\left[F(1,46)=35.94, M S_{\mathrm{e}}=.025\right]$ were significant sources of variance. Furthermore, the effects of indirect strength were somewhat more apparent when direct cueto-target strength was weak than when it was strong. When direct strength was weak, the probabilities of recall for high and low indirect strength were, respectively, .57 and .37 . When direct strength was strong, these probabilities were .79 and .74 . The interaction between direct strength and indirect strength was significant $[F(1,46)=$ 7.81 ], and a Fisher's $L S D=.08$ indicated that, although indirect strength effects were apparent at each level of direct strength, the effect was statistically reliable only when direct strength was weak.

The results of this experiment also indicated that the influence of indirect strength was somewhat more apparent when target set size was large than when it was small. The probabilities of recall for high and low levels of indirect strength were, respectively, .65 and .45 when target set size was large and .71 and .66 when set size was small. The interaction between indirect strength and target set size was significant $\left[F(1,46)=7.85, M S_{\mathrm{e}}=\right.$ .033 , Fisher's $L S D=.07]$. None of the remaining sources in this analysis were reliable $(F \mathrm{~S}<1)$.

Finally, we should note that we replicated Experiment 1 as closely as possible, using a presentation rate of $3 \mathrm{sec}$ instead of $6 \mathrm{sec}$ during the study trial. More generous amounts of study time produce slight increases in recall in the extralist cuing task but have no differential effects on the effects of either direct strength or target set size (Nelson et al., 1992). Nevertheless, the effects of study time on the influence of indirect connections are unknown, so the replication was completed despite doubts that this variable would turn out to be crucial.

Table 1

Probability of Correct Recall as a Function of Target Set Size, Direct Strength, and Indirect Strength in an Extralist

\begin{tabular}{|c|c|c|c|c|}
\hline \multirow{2}{*}{$\begin{array}{l}\text { Indirect } \\
\text { Strength }\end{array}$} & \multicolumn{2}{|c|}{$\begin{array}{l}\text { Small Set Size } \\
\text { Direct Strength }\end{array}$} & \multicolumn{2}{|c|}{$\begin{array}{l}\text { Large Set Size } \\
\text { Direct Strength }\end{array}$} \\
\hline & Strong & Weak & Strong & Weak \\
\hline High & .83 & .59 & .74 & .55 \\
\hline Low & .85 & .46 & .62 & .27 \\
\hline
\end{tabular}
Cuing Task With a 6-sec Presentation Rate 
Table 2

Probability of Correct Recall as a Function of Target Set Size, Direct Strength, and Indirect Strength in an Extralist Cuing Task With a 3-Sec Presentation Rate

\begin{tabular}{cccccc}
\hline & \multicolumn{2}{c}{$\begin{array}{c}\text { Small Set Size } \\
\text { Direct Strength }\end{array}$} & & \multicolumn{2}{c}{$\begin{array}{c}\text { Large Set Size } \\
\text { Direct Strength }\end{array}$} \\
\cline { 2 - 3 } \cline { 5 - 6 } \begin{tabular}{c} 
Indirect \\
\cline { 5 - 6 }
\end{tabular} & Strength & Weak & & Strong & Weak \\
\hline High & .83 & .65 & & .72 & .56 \\
Low & .82 & .44 & & .58 & .28 \\
\hline
\end{tabular}

As shown in Table 2, the findings were very close to those obtained in Experiment 1. Recall was greater for strong directly related cues (.74) than for weakly related cues (.48) and for cues with high (.69) as opposed to low (.53) levels of indirect strength. In addition, the interaction between direct and indirect connection strength was replicated. When direct strength was weak, the probabilities of recall for high and low indirect strength were, respectively, .61 and .37 . When direct strength was strong, these probabilities were .78 and .70 . The results of a mixed-model analysis of variance indicated that direct strength $\left[F(1,38)=31.09, M S_{\mathrm{e}}=.075\right]$, indirect strength $\left[F(1,38)=29.35, M S_{\mathrm{e}}=.029\right]$, and the interaction of these two variables $[F(1,38)=12.68]$ were significant. An $L S D$ of .07 indicated that the effects of indirect strength were reliable at each level of direct strength, but, as in the initial study, the effects of indirect strength were more apparent when direct strength was weaker. In the replication experiment, the effects of target set size were also significant $\left[F(1,38)=31.93, M S_{\mathrm{e}}=.033\right]$, but the interaction between set size and indirect strength found in the initial study was not $(F=2.21)$. No other sources in this analysis even approached the criterion for significance.

\section{EXPERIMENT 2}

The results of Experiment 1 and its replication indicate that indirect connections contribute to cued recall above and beyond the contribution produced by direct connections, although the magnitude of this contribution was somewhat greater when direct connection strength was relatively weaker. The results of the replication suggest that, at least within the range of the rates used, these effects do not appear to depend upon how much time subjects have to elaborate upon their target encoding. The purposes of Experiment 2 were to replicate and extend the facilitation effect produced by indirect connections with different materials and to separate the relative influences of the number of indirect links from the summed strength of these links. In Experiment 1, although the latter index varied over a narrow range, these potential sources of facilitation covaried such that pairs with more indirect connections tended to have stronger indirect connections to their targets. This relationship arises in part because the indirect strength measures are based on the sum of the multiplied strengths linking the test cue and target, and the more links there are, the stronger the indirect connection should be. However, many links do not necessarily engender much higher lev- els of strength, or the reverse. For example, SWEATER WARM has 7 mediated links, but the multiplied and summed strength of all of these connections totals only to .018 , whereas MISSING FOUND has a single mediator with a strength of .16 .

Practically speaking, investigators using weakly related associates in research need to know whether it is better to select or to control indirect connections by choosing items on the basis of the number of such connections or by their estimated strength of connection, or both. Indirect strength effects may arise either because there are many weakly related connections between the cue and the target or because there is a single strong connection between them. As in Experiment 1, subjects studied a single list of words under extralist cuing conditions. The test cues used to prompt the recall of these words were equally related to the targets in terms of the index of direct strength, and they varied in terms of the number and strength of the indirect connections. Cues had either strong or weak indirect connections with their targets and they shared either many or few indirect connections with them.

\section{Method}

Design, Subjects, and Procedures. Both number of indirect connections (many, few) and their relative strengths (strong, weak) were varied within subjects in a $2 \times 2$ design. Twenty participants were selected from the same subject pool used for the first experiment, with one-half of them assigned to one of the lists and the remaining one-half to the other. The study and test trial procedures used in this experiment were the same as those used in Experiment 1 , except that the words were presented for $3 \mathrm{sec}$ instead of 6 sec during study.

Materials. The two lists of cues and targets were constructed by using the norms used for Experiment 1; they are presented in Appendix $B$. Two different measures of indirect connection were calculated again, one based on converging links that occur when words share associates and one based on mediating links leading from cue to mediator to target. The mean number of shared associates were $3.33(S D=.07)$ and $1.00(S D=.00)$, respectively, when test cues shared many and few links with their targets. For the mediation measure, these values were $5.20(S D=1.88)$ and 2.58 $(S D=1.70)$. The two measures of indirect strength based on the number of connections were correlated, as were the comparable measures obtained when strength was calculated according to multiplied and summed values. Strong connections averaged .19 $(S D=.04)$ and weak connections averaged $.007(S D=.007)$ for the shared associates index; they averaged $.20(S D=.05)$ and .016 $(S D=.02)$ for the mediation index. Care was taken to ensure that variations in strength were equated within each level of number of indirect links.

Direct forward st rength was controlled in each of the above conditions at an intermediate level relative to the levels used in Experiment 1 , and it averaged $17(S D=.07)$. Backward strength in the target-to-cue direction was also cont rolled at very low levels in each condition $(M=.02, S D=.04)$. The modal estimate of backward strength was zero. Furthermore, the number of associates linked to each test cue, connectivity among the associates of the target, and target frequency were also controlled. They averaged, respectively, $12.73(S D=3.83), 1.45(S D=.73)$, and $151(S D=$ $186)$. In general, the test cues had a moderate number of associates and were moderately related to their targets in terms of direct strength; targets were equated across conditions in terms of connectivity and frequency. 


\section{Results}

The probabilities of correct cued recall when the test cues shared many indirect links with their targets were .73 and .62 for strong and weak connections, respectively; when the test cues shared few connections, these values were .53 and .31 . These results indicate that cued recall was more likely when the pairs shared many indirect links (.68) than when they shared few indirect links (.42) and when the links were strong (.63) than when they were weak (.47). The results of a repeated measures analysis of variance showed that the number of indirect connections $\left[F(1,19)=58.00, M S_{\mathrm{e}}=.022\right]$ and the strength of these connections $\left[F(1,19)=26.30, M S_{\mathrm{e}}=.020\right]$ had significant effects. Although number of connections appeared to have a greater effect for weaker connections, the interaction between these sources was not reliable $(F=1.31)$.

Similar results were obtained at the item level. The findings of Experiment 2 were subjected to an item analysis that included the 48 pairs of items for the two lists, and the results were then analyzed in multiple regression analyses. Direct strength, number of mediated connections, and strength of the mediated connections were included as variables, with probability of correct recall serving as the dependent measure. The results showed that these variables were significantly related to probability of correct recall $\left[r=.59, F(3,44)=7.90, M S_{\text {res }}=\right.$ $.034]$. The $t$ values and standardized beta coefficients for measures of direct strength, number of mediated connections, and mediated strength were $t=.59(.07), t=$ $3.92(.49)$, and $t=2.02(.25)$, respectively. The effects of direct strength were not reliable in this study because this variable was controlled, but the effects of both number and strength of the mediated connections were significant. Similar results were obtained when the convergent measure was used in place of the mediation measure.

The results of Experiment 2 replicate and extend the results of Experiment 1. Taken together, the findings suggest that indirect connections affect probability of recall in the extralist cuing task, especially when the direct strength between the test cue and target is set at either weak or moderate levels of strength. Furthermore, the findings suggest that both the number and the strength of indirect connections need to be taken into account whenever related words are being selected for experimental work involving extralist cued recall. The effect of number of connections in this experiment is particularly interesting because of how the lists had to be constructed in order to achieve a strong manipulation of indirect strength. In constructing the lists, we realized that, when indirect strength was high and many connections were involved, most of the strength was produced by a single connection, not by the accumulated strength of several moderately strong connections. For example, for ACCELERATE FAST mediated strength was calculated at .146, but .137 of this strength was produced by $1 / 6$ of the connections, that is, the mediator speed. Given that the number of connections affected probability of recall even when indirect strength was high, this constraint implies that even measurably weak indirect connections contributed to recall.

\section{EXPERIMENT 3}

The purpose of Experiment 3 was to determine whether three-step connections contributed to the probability of recall, for example, ACCELERATE-speed-slow-FAST. A computer program was used to calculate the number and strengths of both two- and three-step mediated connections between every normed cue and each of its responses to allow us to examine general relationships for $n=62,501$ pairs of directly related words (converging links were ignored). ${ }^{2}$ The results of these analyses underestimated three-step connections because some associates that might have provided a mediating link had not yet been normed. Nevertheless, the general results were interesting. For example, for two- and three-step connections, directly related pairs of words shared averages of $1.40(S D=1.71)$ and 7.28 links $(S D=10.09)$, respectively. About one-third of the pairs showed no mediated connections, whereas others showed as many as 15 twostep links and as many as 106 three-step links. Hence, taking any pair of associatively related words at random, about $33 \%$ will not have any two- or three-step mediated connections, but many will be more strongly related in terms of the indirect measure than in terms of the direct measure.

Experiment 3 was designed to evaluate the possibility that three-step connections affect cued recall above and beyond effects linked to two-step connections. As in the initial experiment, subjects studied individually presented words for a short period and were then given test cues to prompt the recall of these words. One-half of the test cues shared relatively strong three-step links with their targets, and the remaining one-half shared relatively weak three-step links. The cues were only weakly related to their targets in terms of the direct- and twostep-strength measures, and all other item characteristics that might have affected the outcome of the experiment were controlled.

\section{Method}

Design, Subjects, and Procedures. The experimental design for Experiment 3 involved a single variable, three-step strength, which was manipulated within subjects. Twenty participants were selected from the same subject pool used for the first experiment. One-half of them were tested on one of the lists, and the remaining one-half were tested on the other list. The procedures used in Experiment 1 were also used in this experiment, except that the words were presented for $3 \mathrm{sec}$ during study.

Materials. The norms were used to construct two lists of cues and targets, and they are presented in Appendix C. With three-step strength calculated according to the multiplication rule used in Experiment 1 , one-half of the test cues were strongly related to their targets, averaging .10 when pooled over lists $(S D=.03)$, and the remaining test cues were weakly related, averaging $.009(S D=$ .008 ). The number of three-step links was approximately the same regardless of whether three-step strength was strong $(18.67, S D=$ 
$12.58)$ or weak $(17.21, S D=14.86)$. In addition, direct strength, two-step strength, and number of two-step connections were controlled at each level of three-step strength, averaging, respectively, $.065(S D=.045), .068(S D=.051)$, and $3.48(S D=1.82)$ connections. Furthermore, the number of associates linked to each test cue was controlled at each level of three-step strength so that each cue had approximately 11.85 associates $(S D=4.50)$. In general, the test cues had a moderate number of associates, they were weakly related to their targets in terms of both direct and two-step measures of strength, and they differed only in terms of the measure of three-step strength. Finally, to control target characteristics, the same targets were used for strongly and weakly related test cues. The targets prompted by strongly related cues in List 1 (e.g., BREAKFAST FOOD) were prompted with weakly related test cues in List 2 (e.g., HAMBURGER FOOD), and the reverse.

\section{Results}

The probabilities of recall as a function of three-stepconnection strength were .57 and .51 for strongly and weakly related test cues, respectively. Although the difference was in the expected direction, it was not statistically reliable $[F(1,19)=1.35]$. Null results were also obtained in each of two follow-up experiments using the same procedures but different materials. In the first follow-up experiment, the test cues were more strongly related in terms of direct measures of strength $(M=$ $.17)$; at the three-step level, strongly related cues also shared substantially more three-step connections with their targets (23.42) than did weakly related cues (3.63). A small relative advantage for stronger three-step cues (.61) than for weaker three-step cues (.57) was obtained. In the second follow-up experiment, direct strength was set at weak levels $(M=.08)$, and three-step strength and number of three-step connections were covaried, as in the first follow-up study. Again, there was a small advantage for stronger (.48) than for weaker (.44) three-step connections. When pooled over all three experiments, the relative advantage of stronger three-step connections averaged $5 \%$. To achieve a more powerful test of the three-step strength effect, the findings of Experiment 3 and the two followup studies were analyzed in a single analysis of variance that included experiment and three-step strength as variables. This analysis indicated that experiment $[F(2,57)=$ $\left.3.78, M S_{\mathrm{e}}=.049, L S D=.10\right]$ and three-step strength $\left[F(1,57)=3.89, M S_{\mathrm{e}}=.016\right]$ were significant sources of variation. The interaction was not reliable $(F<1)$.

The three-step strength effect found in the pooled data was small but reliable, but this effect failed to hold up at the item level. The cue-target pairs used in Experiment 3 and in the two follow-up studies were subjected to an item analysis, and the results were evaluated in a multiple regression analysis involving direct cue-to-target strength, number of two-step connections, and number of three-step connections. As in Experiment 2, probability of correct recall served as the dependent variable. The results showed that these variables were significantly related to probability of correct recall $[r=.29, F(3,140)=$ $\left.4.34, M S_{\text {res }}=.057\right]$. For direct strength and for the number of two-step connections, the $t$ values and standardized beta coefficients were, respectively, $t=2.75(.22)$ and $t=2.01$ (.28). Each of these values contributed significantly to probability of recall. However, the number of three-step connections had a nonsignificant effect on recall, $t=1.76(-.24)$.

When estimates of two-step and three-step strength were entered into the analysis in place of the estimates of the number of cue-to-target connections, recall varied significantly with direct strength, $t=3.18(.27)$, but neither two-step nor three-step connection strength had a significant relation to recall. These patterns were not substantially altered when other significant predictors of recall, such as connectivity among the associates of the target (Nelson et al., 1993) and target frequency (Nelson $\& \mathrm{Xu}, 1995)$, were entered into the regression equation. Nor were different conclusions reached when the findings from Experiments 1-3 and the follow-up studies were included in a regression analysis involving all 288 cue-target pairs. In light of the weak effects found in the analyses of variance and the null effects found at the item level in the regression analyses, the findings suggest that three-step connections contribute small and mostly inconsequential benefits to recall in the extralist cuing task.

\section{EXPERIMENT 4}

The results of Experiments 1 and its extensions support the conclusion that indirect two-step connections add to the facilitation produced by direct connections in the extralist cuing task, particularly when the normatively determined index of direct strength was set at weaker levels. This conclusion was also evaluated in Experiment 4 , but the participants in this experiment studied the test cues and target words paired together in an intralist cuing task as opposed to studying targets in the absence of their cues.

As in the initial experiments, interest was focused on the potential contribution of indirect connections. However, with direct connection strength set at the levels used in Experiment 1, studying the pairs together in the intralist task was expected to overshadow the effects of indirect connections. Therefore, direct connection strength was set at weak or at very weak levels in Experiment 4. In essence, we conceptualized the two experiments as parallel studies in which the direct-strength measure was adjusted downward to accommodate performance differences between extralist and intralist cuing tasks. Weakly related pairs were directly connected according to the norms, in that targets were given as associates of their cues in free association by only a small proportion of the subjects. In contrast, for very weakly related pairs, neither word appeared as a direct associate of the other in the normative database. ${ }^{3}$ This variable was crossed with indirect connection strength, and, as in Experiment 1, we expected to find that the presence of indirect connections would be more apparent for the most weakly related pairs. As in Experiment 1, target set size was also varied, but, more importantly, the pairs were presented at either fast or slow rates. The purpose of manipulating 
study time was to determine whether variations in the influence of indirect connections would be affected by elaborative processes occurring during the study trial. If so, such effects might reflect the influence of encoding processes occurring in the intralist cuing task. Alternatively, the absence of such dependencies would be consistent with the assumption that such effects were largely determined by processes occurring during retrieval. Such a result would be consistent with previous findings indicating that, although presentation rate has reasonably large effects in the intralist task, it does not appear to differentially influence effects linked to either direct connection strength or target set size (Nelson et al., 1992).

\section{Method}

Design and Subjects. The experimental design formed a $2 \times$ $2 \times 2 \times 2$ mixed-model factorial. Study time ( 2 and $6 \mathrm{sec}$ ) and direct cue-to-target strength (weak, very weak) were varied between subjects. Indirect strength and target set size were varied within subjects. Eighty people served in the experiment, with 20 assigned to each between-subjects condition and 10 assigned to each list.

Materials and Procedure. The procedures for Experiment 4 were identical to those used for Experiment 1, except that the instructions were adjusted to accommodate the presentation of the test cue with the target during study. The subjects were told that pairs of words would be presented, that they should try to remember as many pairings as possible, and that the words appearing on the left side would be presented later to prompt recall of the words appearing on the right. With the exceptions of differences in presentation rate and instructions, the general procedures were identical to those used for the extralist cuing conditions of Experiment 1 , including the use of self-pacing at test.

New sets of lists were constructed for this experiment, and they are presented in Appendix D. The lists consisted of 24 pairs of weakly related words and 24 pairs of very weakly related words. As before, the weakly related cues produced their targets directly at a relatively low probability in the normative database, $.10(S D=$ .02 ). The very weakly related words did not produce one another as associates at all. Indirect strength was varied by selecting pairs of words from the norms having varying numbers of shared associates. The number of shared associates at high and low levels of indirect strength were, respectively, $3.40(S D=.94)$ and $.38(S D=$ .49). The number of two-step mediated connections did not differ at each level of shared associates, averaging .49 mediated connections $(S D=.80)$ for high sharing and .56 mediated connections for low sharing $(S D=1.22)$.

Target set size averaged $7.20(S D=1.30)$ and $21.96(S D=3.6)$ for words with small and large associative sets. Cue set size was held constant, as in the previous experiments, averaging 15.89 associates per cue ( $S D=5.17)$. In addition, target concreteness, frequency, and connectivity were also equated within each condition. The respective means were $4.70(S D=1.33), 141(S D=184)$, and $1.38(S D=.68)$.

\section{Results}

Probability of correct recall as a function of the principal conditions of the experiment are shown in Table 3. As can be seen, probability of recall varied substantially over the manipulations. In general, it was higher when study time was more generous (.64) than when it was not (.45) and when the direct strength of the word pairs was weak $(.81)$ than when direct strength was very weak $(.28)$. The results of a mixed-model analysis of variance indicated that the effects of both presentation rate $[F(1,76)=$
Table 3

\begin{tabular}{|c|c|c|c|c|}
\hline \multirow{2}{*}{$\begin{array}{l}\text { Indirect } \\
\text { Strength }\end{array}$} & \multicolumn{2}{|c|}{$\begin{array}{l}\text { Small Set Size } \\
\text { Direct Strength }\end{array}$} & \multicolumn{2}{|c|}{$\begin{array}{l}\text { Large Set Size } \\
\text { Direct Strength }\end{array}$} \\
\hline & Weak & Very Weak & Weak & Very Weak \\
\hline \multicolumn{5}{|c|}{ 2-sec Study Rate } \\
\hline High & .71 & .20 & .73 & .20 \\
\hline Low & .78 & .19 & .69 & .13 \\
\hline \multicolumn{5}{|c|}{ 6-sec Study Rate } \\
\hline High & .94 & .52 & .83 & .37 \\
\hline Low & .93 & .40 & .87 & .28 \\
\hline
\end{tabular}

$\left.40.39, M S_{\mathrm{e}}=.07\right]$ and level of direct strength $[F(1,76)=$ 314.14] were significant. Interestingly, even a weak direct connection produces a substantially higher level of recall than does the apparent absence of any direct connection.

What is more important for present purposes, indirect connections affected recall but only for very weakly related pairs. The recall of weakly related pairs for high and low levels of indirect strength were .80 and .81 . Comparable probabilities for very weakly related pairs were .32 and .25 . The interaction between direct and indirect strength was significant $\left[F(1,76)=4.21, M S_{\mathrm{e}}=\right.$ $.036, L S D=.06$ ]. A separate experiment using different sets of very weakly related materials was omitted to conserve space, but it showed a similar benefit for indirect connections.

None of the other important interactions that could have emerged in this experiment were significant (all $F \mathrm{~s}<1$ ), including interactions involving presentation rate and the indices of direct and indirect strength. Hence, the effects of direct and indirect connections appear to be largely limited to retrieval, as expected. Finally, although reduced in comparison to what is typically found in the extralist cuing task, recall also varied with target set size. Recall for targets with smaller associative sets (.58) was greater than that for those with larger associative sets $(.51)\left[F(1,76)=13.49, M S_{\mathrm{e}}=.032\right]$. This effect was somewhat smaller after the faster rate of presentation than after the slower rate $[F(1,76)=3.98]$.

\section{GENERAL DISCUSSION}

The present experiments produced three new findings. First, normatively measured indirect connections involving a retrieval cue and its target can facilitate cued recall. Such facilitation is found regardless of whether the retrieval cue is studied with the target or presented only during testing as an aid to recall. Second, indirect connections tend to contribute more to recall when the normatively measured direct connection is weaker than when it is stronger. Such connections increase the probability of successful target retrieval, particularly when that retrieval is largely uncertain in the first place. Third, although two-step connections facilitate cued recall, three-step connections between the test cue and target 
appear to contribute very little even when direct and twostep connections are relatively weak.

These findings carry both methodological as well as theoretical implications. The first two findings place constraints on using free-association norms to predict performance in cued recall. Traditional normative methods for assessing preexisting strength between two related words are insufficient. Investigators interested in cued recall cannot assume that strength has been effectively manipulated or controlled by selecting pairs of related words only on the basis of the index of direct strength provided by the proportion of subjects responding to a given word. For example, DUNE produces BEACH with a probability of .02 , but these two words have three indirect connections that may add as much as .39 to the strength of their connection according to the multipliedsummed algorithm. Indirect strength between these two words is stronger than direct strength according to the norms. SIMILAR produces DIFFERENT with a probability of .22 , and indirect connections add .28 to the strength of this relationship. In this case, direct and indirect connections appear to contribute about equally to the strength of the relationship. Examples illustrating all possible combinations of direct and indirect strength abound, indicating that there is not likely to be a general relationship between these characteristics so that one can be predicted from the other.

These findings imply that researchers need to be wary of depending solely on estimates of direct strength to control preexisting strength. Similar cautions may apply in other types of memory tasks such as lexical decision, naming, and so on, but this point remains to be evaluated. Response latency and response accuracy may respond to different psychological processes (e.g., MacLeod \& Nelson, 1984), and tasks such as lexical decision may be relatively insensitive to manipulations of indirect connections (but see McKoon \& Ratcliff, 1992; McNamara, 1992). Nevertheless, caution seems to be especially warranted when very weakly related pairs of items are selected, because indirect connections appear to play an especially important role in the processing of such pairs. If part of the purpose of an experiment is to estimate the effects of preexisting strength on performance, the influence of this variable will be underestimated to the extent that the more weakly related pairs share indirect connections. If the purpose of the experiment simply requires the selection of weakly related pairs, then considerable variability could still result from the failure to control indirect connections. Furthermore, the criterion of no direct association is no guarantee that two words are associatively unrelated.

These considerations suggest that the precision of experiments involving related pairs of words can be improved by using association norms to estimate the potential contribution of both direct and indirect connections. In this regard, it would be useful to have an index of net associative strength that incorporates the full range of connections between two related words and expresses this relationship in a single numerical value. The present experiments indicate that direct and indirect connections contribute to the overall strength of a cue-target relationship, and other findings associated with the extralist cuing task indicate that the backward (target-to-cue) connection is also important (Nelson, McKinney, Gee, \& Janczura, in press). One way to capture all three types of connections relies on a variation of the algorithm for computing Gillund and Shiffrin's (1984) concept of familiarity, with net preexisting strength given by (also see Ratcliff \& McKoon, 1988)

$$
S\left(Q_{j}, T_{i}\right)=\sum_{k} S_{j k}^{W_{4}} S_{i k}^{W_{t}}
$$

where $Q_{j}$ is the test cue, $T_{i}$ is the target, and $k$ are all the associates that link the two words, including each other, and $W_{q}$ and $W_{t}$ are the weights on test cue and target strengths, with the weights varying from 0 to 1 . Test-cue strengths presumably should be weighted more heavily than target strengths because they reflect currently activated as opposed to residual strengths. The context cue that is normally present in the calculation of familiarity in SAM is absent in the calculation of net preexisting strength on the assumption that context plays no role in the representation of connection strengths between lexical representations created as a result of hundreds, if not thousands, of experiences with the items in different contexts. Furthermore, when items are not connected in terms of normative measurement, the strengths are set to zero in contrast to being set to some residual value as is done in SAM in the simulation of recognition.

Equation 1 is illustrated in two numerical examples in Table 4. In the retrieval structure for a particular test cue and target, the self-strength of a cue or a target to its own lexical representation is set to 1.0. All other strengths are set to values of connection strengths determined by freeassociation norms, and the calculation of cue-to-target strength is made with the weights set to 1.0 to simplify the presentation. These examples demonstrate several characteristics of the equation that are relevant to developing an index of net preexisting strength between two related words. First, note that net strength is a function of forward cue-to-target connections, backward targetto-cue connections, and the strengths of the indirect connections linking these two items. Stronger forward and backward connections contribute to higher levels of preexisting strength, as do the number and strength of indirect connections. For example, the two numerical illustrations show differences in indirect strength given similar levels of forward and backward strength. Hence, other things being equal, the equation predicts that the probability of recalling a target in the presence of a related cue will increase with the overall connections between the cue and target. Second, note that each type of connection contributes independently to net preexisting strength, so that any one link can be missing in terms of the normative measurement and yet measurable levels of strength can be present. For example, as suggested in 
Table 4

\begin{tabular}{|c|c|c|c|c|c|}
\hline $\begin{array}{c}\text { Cue } \\
\text { Target }\end{array}$ & $\begin{array}{l}\text { Cue } \\
S_{11} \\
S_{21} \\
\end{array}$ & $\begin{array}{c}\text { Target } \\
S_{12} \\
S_{22} \\
\end{array}$ & $\begin{array}{c}\text { Indirect l } \\
S_{13} \\
S_{23}\end{array}$ & $\begin{array}{c}\text { Indirect } 2 \\
S_{14} \\
S_{24} \\
\end{array}$ & $\begin{array}{c}\text { Indirect } 3 \ldots \\
S_{15} \\
S_{25}\end{array}$ \\
\hline \multicolumn{6}{|c|}{ Example 1} \\
\hline & SORE & PAIN & HURT & $\mathrm{ACHE}$ & $\mathrm{OUCH}$ \\
\hline SORE & 1.00 & .12 & .28 & .06 & .01 \\
\hline PAIN & .00 & 1.00 & .55 & .01 & .03 \\
\hline \multicolumn{6}{|c|}{ Example 2} \\
\hline & CONTINENT & COUNTRY & LAND & USA & AMERICA \\
\hline CONTINENT & 1.00 & .13 & .13 & .05 & .03 \\
\hline COUNTRY & .01 & 1.00 & .02 & .18 & .08 \\
\hline
\end{tabular}

With the weights set to 1.00 , the strengths related to the test cue and target are not differentially weighted, so that:

$$
\begin{aligned}
& S\left(Q_{j}, T_{i}\right)=\sum_{k} S_{j k} S_{i k} \\
S(\text { SORE, PAIN })= & S_{11} S_{21}+S_{12} S_{22}+S_{13} S_{23}+S_{14} S_{24}+S_{15} S_{25} \\
= & 1.0 \times .00+.12 \times 1.0+.28 \times .55+.06 \times .01+.01 \times .03 \\
= & .278 \\
S(\text { CONTINENT, COUNTRY })= & S_{11} S_{21}+S_{12} S_{22}+S_{13} S_{23}+S_{14} S_{24}+S_{15} S_{25} \\
= & 1.0 \times .01+.13 \times 1.0+.13 \times .02+.05 \times .18+.03 \times .08 \\
= & .154
\end{aligned}
$$

Experiment 4, direct forward and backward connections may not be detectable in terms of the norms, but the cue and target can be related through indirect connections and recall of the target in the presence of the test cue is predicted to be facilitated as a function of the strength of such connections. Furthermore, because each type of connection contributes independently, some of these connections can be ignored for certain purposes. For example, when an experiment calls for exceptionally strong direct connections, the relative contribution of the indirect connections can be left out or given less weight in the calculations. Finally, as conceptualized, the equation contains no allowance for three-step connections between the test cue and the target and, by default, predicts that such connections will have little or no effect on cued recall.

Equation 1 does not constitute a model of cued recall in and of itself. At the least, such a model would have to incorporate explanations for the effects of presentation rate, levels of processing, and so on, as well as the effects of frequency, concreteness, set size, and associative connectivity (Nelson et al., 1993; Nelson \& Schreiber, 1992; Nelson et al., 1992; Nelson \& Xu, 1995). The equation merely serves as one seemingly reasonable means for making better use of free-association norms to capture the complexity of the connections that can relate two words. Of course, if this index of net strength is superior to using the direct measure typically employed in studies of memory, it should account for additional variance. To evaluate this possibility, the 144 cue--target pairs used in the extralist cuing tasks of Experiments 1 and 2 were subjected to a multiple regression analysis with direct forward strength and net strength calculated with Equation 1 included as variables. The results showed that these variables were significantly related to probability of correct recall $\left[r=.54, F(2,141)=28.66, M S_{\text {res }}=.043\right]$. The $t$ values (and standardized beta coefficients) for measures of direct strength and net strength, respectively, were $t=2.45(.21)$ and $t=4.64(.39)$. The effects of both variables were significant, indicating that the addition of information about target-to-cue strength and indirect strength contributes significantly to the predictive value of direct forward strength, at least in the cuing task. This pattern was not changed when backward strength was dropped from the equation, suggesting that indirect strength alone adds significantly to predictions based on forward strength alone.

The results of the main regression analysis indicate that the proposed index of net preexisting strength may be superior to using direct strength in at least some circumstances, but several additional points need to be considered. First, the above analysis was performed with the weights related to cues and targets set to 1.0 . Weighting the test cue more strongly than the target should improve prediction, because the cue is present at test and the connections to the target that it activates are likely to account for more variance than the connections from the target to the cue and its associates. This is particularly likely to be the case in the extralist cuing task, where the test cue and target have never been studied together in the experimental context and the target must be recalled from memory in the presence of the test cue. Second, using untransformed strengths obtained from the association norms in Equation 1 assumes a linear relationship be- 
tween the normatively determined probabilities of response production and recall. Given the direct-strength levels employed in the present extralist cuing experiments and in our previous experiments with this task, this assumption is not unreasonable and has, in fact, been verified in an as yet unpublished study in our lab. However, when the entire scale of probability of response production is considered, transformations of the raw normative values are likely to lead to more accurate predictions. The nature of such transformations remains to be explored.

Finally, we want to emphasize that Equation 1 is not theoretically neutral, because other equations based on other models of associative processes may produce different net-strength values and may prove to be superior. Some equations may serve as better predictors in one task, whereas other equations may be better in another task. We assumed at the outset that associative norms were extremely useful for predicting performance in cued recall, and the main point of the present experiments was simply to determine whether taking indirect connections into account would improve this predictability. The question of whether Equation 1 is or is not the best way to incorporate such connections remains moot but will hopefully stimulate others into thinking about ways in which the complexity of connections among related words can be captured in a single index.

\section{REFERENCES}

BAHRICK, H. P. (1970). Two-phase model for prompled recall. Psychological Review, 77, 215-222.

CANAS, J. J. (1990). Associative strength effects in the lexical decision task. Quarterly Journal of Experimental Psychology, 42A, 121-145.

Cofer, C. N. (1968). Convergent association: Additional evidence. Journal of Verbal Learning \& Verbal Behavior, 7, 265-267.

Cramer, P. (1968). Word association. New York: Academic Press.

DEESE, J. (1965). The structure of associations in language and thought. Baltimore: Johns Hopkins University Press.

peGroot, A. M., Thomassen, A. J., \& Hudson, P. T. (1982). Associative facilitation of word recognition as measured from a neutral prime. Memory \& Cognition, 10, 358-370.

Gillund, G., \& ShifFrin, R. M. (1984). A retrieval model for both recognition and recail. Psychological Review, 91, 1-67.

JENKINS, J. J. (1963). Mediated associates: Paradigms and situations. In C. N. Cofer \& B. S. Musgrave (Eds.), Verbal behavior and learning (pp. 210-245). New York: McGraw-Hill.

Kahneman, D., \& Miller, D. T. (1986). Norm theory: Comparing reality to its alternatives. Psychological Review, 93, 136-153.

KUČERA, H., \& FRANCIS, W. N. (1967). Computational analysis of present-day American English. Providence, RI: Brown University Press.

MacLeod, C. M., \& Nelson, T. O. (1984). Response latency and response accuracy as measures of memory. Acta Psychologica, 57, 215-235.

MCEvoy, C. L. (1988). Automatic and strategic processes in picture naming. Journal of Experimental Psychology: Learning, Memory, \& Cognition, 14, 618-626.

McEvoY, C. L., \& NELSON, D. L. (1982). Category names and instance norms for 106 categories of various sizes. American Journal of Psychology, 95, 581-634.

McKoon, G., \& RatClifF, R. (1992). Spreading activation versus compound cue accounts of priming: Mediated priming revisited. Journal of Experimental Psychology: Learning, Memory, \& Cognition, 18. 1155-1172.

McNamara, T. P. (1992). Theories of priming: I. Associative distance and lag. Journal of Experimental Psychology: Learning. Memory, \& Cognition, 18, 1173-1190.

Nelson, D. L., Bennett, D. J., Gee, N. R., Schreiber, T. A., \& MCKINNEY, V. (1993). Implicit memory: Effects of network size and in terconnectivity on cued recall. Journal of Experimental Psychology: Learning, Memory, \& Cognition, 19, 747-764.

NeLson, D. L., \& MCEvoY, C. L. (1979). Encoding context and set size. Journal of Experimental Psychology: Human Learning \& Memory, 5, 292-314.

Nelson, D. L., McEvoy, C. L., \& Schreiber, T. A. (1994). The University of South Florida word association, rhyme, and word frag ment norms. Unpublished manuscript.

Nelson, D. L., McKinney, V. M., Gee, N. R., Janczura, G. A. (in press). Interpreting the influence of implicitly activated memories on recall and recognition. Psychological Review.

Nelson, D. L., \& Schreiber, T. A. (1992). Word concreteness and word structure as independent determinants of recall. Journal of Memory \& Language, 31, 237.260.

Nelson, D. L., Schreiber, T. A., \& McEvoy, C. L. (1992). Processing implicit and explicit representations. Psychological Review, 99, 322 348.

NeLsON, D. L., \& XU, J. (1995). Effects of implicit memory on explicit recall: Set size and word frequency effects. Psychological Research, 57, 203-214.

RATCLIFF, R., \& MCKoon, G. (1988). A retrieval theory of priming Psychological Review, 95, 385-408.

\section{NOTES}

1. PIER stands for processing implicit and explicit representations.

2. The program for determining these values was developed by Thomas Schreiber at the University of Kansas.

3 . We refer to such pairs as very weakly reiated rather than as unrelated on the assumption that the norms may not be sensitive enough to detect exceptionally weak direct relationships. Our question was not whether there was or was not a direct relationship between the pairs but whether indirect connections measured through the use of association norms would facilitate recall in the apparent absence of a direct connection measured by the same procedures. 
APPENDIX A

Materials for Experiment 1

\begin{tabular}{|c|c|c|c|}
\hline Test Cue & Target & Test Cue & Target \\
\hline \multicolumn{2}{|c|}{ Strong Cues List 1} & \multicolumn{2}{|c|}{ Weak Cues List 1} \\
\hline BLADE & RAZOR & EDGE & RAZOR \\
\hline LADY & WOMAN & FEMALE & WOMAN \\
\hline VISION & SIGHT & MEMORY & REMEMBER \\
\hline ADJECTIVE & NOUN & SNACK & MUNCH \\
\hline CORAL & REEF & DETERGENT & LAUNDRY \\
\hline BUTTER & MARGARINE & MOSQUITO & INSECT \\
\hline MONARCH & KING & RULER & KING \\
\hline FOOT & TOE & FRIEND & PAL \\
\hline SIGN & STOP & END & STOP \\
\hline FROG & TOAD & WART & TOAD \\
\hline CLENCH & FIST & FIGHT & FIST \\
\hline LIGHT & BULB & LAMP & BULB \\
\hline CAPABILITY & ABILITY & POTENTIAL & ABILITY \\
\hline TRUCK & CAR & TRAIN & CAR \\
\hline RAG & CLOTH & SILK & CLOTH \\
\hline CLARINET & FLUTE & INSTRUMENT & FLUTE \\
\hline LIKE & LOVE & KINDNESS & LOVE \\
\hline COLLEGE & SCHOOL & HOMEWORK & SCHOOL \\
\hline WRECK & ACCIDENT & TRAGEDY & ACCIDENT \\
\hline WICKER & BASKET & WASTE & BASKET \\
\hline BASEBALL & $\mathrm{BAT}$ & CAVE & BAT \\
\hline TRIP & FALL & STAND & FALL \\
\hline COKE & DRINK & GLASS & DRINK \\
\hline SMOKE & FIRE & HEAT & FIRE \\
\hline \multicolumn{2}{|c|}{ Strong Cues List 2} & \multicolumn{2}{|c|}{ Weak Cues List 2} \\
\hline WRITER & AUTHOR & POET & AUTHOR \\
\hline ALIKE & SIMILAR & SAME & SIMILAR \\
\hline SPOUSE & WIFE & TRIANGLE & RECTANGLE \\
\hline PIN & NEEDLE & ORCHESTRA & SYMPHONY \\
\hline LUNCH & DINNER & RUBY & EMERALD \\
\hline KNUCKLE & FIST & DINNER & MEAL \\
\hline STATUE & LIBERTY & BELL & LIBERTY \\
\hline SKINNY & THIN & TALL & THIN \\
\hline LIGHTNING & THUNDER & RAIN & THUNDER \\
\hline DUCK & POND & FROG & POND \\
\hline SPEED & FAST & RUN & FAST \\
\hline BURST & BUBBLE & GUM & BUBBLE \\
\hline PEAR & APPLE & ORANGE & APPLE \\
\hline COURAGE & BRAVE & COWARD & BRAVE \\
\hline TOTE & CARRY & LIFT & CARRY \\
\hline BURY & DEAD & $\mathrm{DIE}$ & DEAD \\
\hline DEFINITION & MEANING & PURPOSE & MEANING \\
\hline SHORTS & PANTS & SKIRT & PANTS \\
\hline BAT & BALL & HIT & BALL \\
\hline SKATE & BOARD & SURF & BOARD \\
\hline GATHER & COLLECT & CALL & COLLECT \\
\hline MAT & DOOR & OPENING & DOOR \\
\hline EXPRESSION & FACE & MIRROR & FACE \\
\hline JUMP & ROPE & PIN & SEW \\
\hline
\end{tabular}

Note - Starting with the first set of targets in each list, the words have small associative sets and many indirect connections with their cues, small associative sets and few indirect connections, large associative sets and many indirect connections, and finally, with the last set, the words have large associative sets and few indirect connections. 
APPENDIX B

Materials for Experiment 2

\begin{tabular}{|c|c|c|c|}
\hline \multicolumn{2}{|c|}{ List 1} & \multicolumn{2}{|c|}{ List 2} \\
\hline Test Cue & Target & Test Cue & Target \\
\hline ACCELERATE & FAST & WOODS & TREE \\
\hline WOUND & HURT & HUMOR & LAUGH \\
\hline LEAN & FAT & SORE & PAIN \\
\hline JEWEL & RING & VISION & SEE \\
\hline UNUSUAL & WEIRD & END & START \\
\hline CHORUS & SONG & BENCH & CHAIR \\
\hline ANCHOR & BOAT & FAR & CLOSE \\
\hline MISSING & FOUND & SIMPLE & HARD \\
\hline PASTE & STICKY & TOAST & BUTTER \\
\hline LAWN & GREEN & EVENING & DAY \\
\hline EVIL & BAD & VESSEL & BOAT \\
\hline LINEN & BED & ACCOUNT & MONEY \\
\hline ACORN & SQUIRREL & READ & WRITE \\
\hline SWEATER & WARM & PAINT & COLOR \\
\hline FLOUR & BAKE & FLUID & LIQUID \\
\hline BOTTLE & COKE & ACT & THEATER \\
\hline INSECT & MOSQUITO & HOLINESS & CHURCH \\
\hline CONTINENT & COUNTRY & STRANGE & ODD \\
\hline CENTURY & YEAR & FUMES & GAS \\
\hline CONTEST & WIN & TELEPHONE & NUMBER \\
\hline ASSISTANT & MANAGER & BUMP & SPEED \\
\hline WAX & SHINE & RAIN & SNOW \\
\hline CALM & QUIET & WIDTH & HEIGHT \\
\hline HEIGHTS & BUILDING & HARMONY & PEACE \\
\hline
\end{tabular}

Note-The first 6 cues in each list share strong and many indirect connections with their targets, the next 6 share strong and few indirect connections with their targets, the next 6 share weak and many connections, and the last 6 share weak and few connections.
APPENDIX C Materials for Experiment 3

\begin{tabular}{|c|c|c|c|}
\hline \multicolumn{2}{|c|}{ List 1} & \multicolumn{2}{|c|}{ List 2} \\
\hline Test Cue & Target & Test Cue & Target \\
\hline CRUISE & WATER & AUTUMN & SUMMER \\
\hline AUTHOR & WRITE & BREAKFAST & FOOD \\
\hline CENT & DIME & FINISHED & START \\
\hline THERMOMETER & COLD & ANGER & SAD \\
\hline MONASTERY & CHURCH & KNIT & NEEDLE \\
\hline MUSK & SMELL & INTELLIGENT & STUPID \\
\hline PLUS & $\mathrm{ADD}$ & REQUEST & ANSWER \\
\hline PUPPY & KITTEN & PRINCESS & QUEEN \\
\hline NIECE & AUNT & DISTANT & CLOSE \\
\hline DISSIMILAR & DIFFERENT & DAWN & DAY \\
\hline OVAL & CIRCLE & LENIENT & SOFT \\
\hline MARS & EARTH & WOODWIND & MUSIC \\
\hline FALL & SUMMER & BARREL & WATER \\
\hline HAMBURGER & FOOD & DESK & WRITE \\
\hline ENGAGE & START & COIN & DIME \\
\hline HURT & SAD & COOLER & COLD \\
\hline PINE & NEEDLE & BLESSING & CHURCH \\
\hline DOPE & STUPID & MUSTY & SMELL \\
\hline STATEMENT & ANSWER & CALCULATE & $\mathrm{ADD}$ \\
\hline PRINCE & QUEEN & MEOW & KITTEN \\
\hline FAR & CLOSE & RELATIVE & AUNT \\
\hline HOUR & DAY & CHANGE & DIFFERENT \\
\hline BED & SOFT & HOOP & CIRCLE \\
\hline SING & MUSIC & GLOBE & EARTH \\
\hline
\end{tabular}

Note-The first set of 12 test cues in each list have strong three-step connections with their targets, and the second set have weak three-step connections with their targets.

APPENDIX D

Materials for Experiment 4

\begin{tabular}{|c|c|c|c|c|c|}
\hline \multicolumn{3}{|c|}{ List 1} & \multicolumn{3}{|c|}{ List 2} \\
\hline $\begin{array}{c}\text { Test Cue } \\
\text { (Weak Direct) } \\
\end{array}$ & $\begin{array}{c}\text { Test Cue } \\
\text { (Very Weak Direct) }\end{array}$ & Target & $\begin{array}{c}\text { Test Cue } \\
\text { (Weak Direct) }\end{array}$ & $\begin{array}{c}\text { Test Cue } \\
\text { (Very Weak Direct) }\end{array}$ & Target \\
\hline LACK & WILL & NEED & CIGARETTE & CLOVE & CIGAR \\
\hline FOG & SILK & CLOUD & SHEEP & PEOPLE & HERD \\
\hline GIANT & HUSK & HUGE & RABBIT & FROG & BUNNY \\
\hline FOAM & TOWEL & BUBBLE & EMERALD & LIME & GEM \\
\hline ESCAPE & PASS & EXIT & DETERGENT & SHAMPOO & LAUNDRY \\
\hline ENDING & RESULT & LAST & SMALL & CLASS & LITTLE \\
\hline CHECK & ANT & CASH & TOOTH & LICE & BRUSH \\
\hline HELPER & ABOVE & AID & PICKLES & PICTURE & CUCUMBER \\
\hline FOCUS & PIANO & CAMERA & CAN & CHARM & ALUMINUM \\
\hline ALLEY & LIME & CAT & RIGHT & PURPLE & CORRECT \\
\hline OCTOPUS & OFFICER & EIGHT & DUNGEON & DISH & DARK \\
\hline MORNING & DISCUSS & EARLY & ELEGANT & STOVE & $\mathrm{RICH}$ \\
\hline CUDDLE & STICK & BEAR & OFFEND & ACCIDENT & INSULT \\
\hline MAGAZINE & SIGN & NEWSPAPER & MOIST & CLAY & DAMP \\
\hline STATE & HEAVY & CITY & SUBTLE & SHELTER & DISCREET \\
\hline HIGHWAY & BOARD & CAR & ISSUE & FORM & NEWS \\
\hline AVOID & HARSH & IGNORE & COUNT & QUARTER & TEN \\
\hline METAL & BUTTON & IRON & HOBBY & ACCEPT & INTEREST \\
\hline SHOCK & SOFA & ELECTRIC & SAFE & SCORE & DANGER \\
\hline VERB & VEST & ACTION & HINGE & HOG & SWING \\
\hline CHEW & MUSEUM & CRUNCH & COMFORTABLE & COMPASS & RELAX \\
\hline CUT & TRIM & BLOOD & PRIVATE & PRODUCT & ALONE \\
\hline BEARD & BEAM & FACE & OPINION & ORANGE & FACT \\
\hline TRADITION & PRUNE & FAMILY & STRAWBERRY & SPEAK & FIELD \\
\hline
\end{tabular}

Note-Starting with the first set of targets in each list, the words have small associative sets and many indirect connections with their cues, small associative sets and few indirect connections, large associative sets and many indirect connections, and finally, with the last set, large associative sets and few indirect connections. 